\title{
Microarray-based comparative genomic hybridisation of breast cancer patients receiving neoadjuvant chemotherapy
}

\author{
J-Y Pierga 1,2, JS Reis-Filho', SJ Cleator',6, T Dexter', A MacKay', P Simpson ',7, K Fenwick', M Iravani', J Salter ${ }^{3}$, \\ M Hills ${ }^{3}$, C Jones ${ }^{4}$, A Ashworth', IE Smith ${ }^{5}$, T Powles ${ }^{5}$ and M Dowsett ${ }^{*, 1,3}$ \\ 'Breakthrough Breast Cancer Research Center, The Institute of Cancer Research, London, SW3 6JB, UK; ${ }^{2}$ Medical Oncology Department, Institut Curie, \\ Paris, cedex 5, France; ${ }^{3}$ Academic Department of Biochemistry, Royal Marsden Hospital NHS Trust, Fulham Road, London, SW3 6Jj, UK; ${ }^{4}$ Section of \\ Paediatric Oncology, Institute of Cancer Research, London, SM2 5NG, UK; ${ }^{5}$ Breast Cancer Unit, Royal Marsden Hospital, London, SW3 6JJ, UK
}

\begin{abstract}
We analysed the molecular genetic profiles of breast cancer samples before and after neoadjuvant chemotherapy with combination doxorubicin and cyclophosphamide (AC). DNA was obtained from microdissected frozen breast core biopsies from 44 patients before chemotherapy. Additional samples were obtained before the second course of chemotherapy (D2I) and after the completion of the treatment (surgical specimens) in 17 and 21 patients, respectively. Microarray-based comparative genome hybridisation was performed using a platform containing 5800 bacterial artificial chromosome clones (genome-wide resolution: $0.9 \mathrm{Mb}$ ). Analysis of the 44 pretreatment biopsies revealed that losses of 4p, 4q, 5q, | $2 q|3.1|-|2 q| 3.12,17 p \mid 1.2$ and $17 q \mid 1.2 ;$ and gains of Ip, 2p, 7q, 9p, II, $19 p$ and $19 q$ were significantly associated with oestrogen receptor negativity. I6q2I -q22.I losses were associated with lobular and 8q24 gains with ductal types. Losses of $5 q 33.3-q 4$ and I8p I I.3I and gains of 6p25.I-p25.2 and Xp I I.4 were associated with HER2 amplification. No correlations between DNA copy number changes and clinical response to AC were found. Microarray-based comparative genome hybridisation analysis of matched pretreatment and D2I biopsies failed to identify statistically significant differences, whereas a comparison between matched pretreatment and surgical samples revealed a statistically significant acquired copy number gain on I | p |5.2- I I | I5.5. The modest chemotherapy-driven genomic changes, despite profound loss of cell numbers, suggest that there is little therapeutic selection of resistant non-modal cell lineages.
\end{abstract}

British Journal of Cancer (2007) 96, 34I-35I. doi:I0.1038/sj.bjc.6603483 www.bjcancer.com

Published online 28 November 2006

(c) 2007 Cancer Research UK

Keywords: breast cancer; comparative genomic hybridisation; microarrays; neoadjuvant chemotherapy

Breast cancer is a heterogeneous disease comprising tumours with remarkably distinct clinical behaviour (Simpson et al, 2005). In the last 20 years, a multitude of prognostic and predictive markers have been tested, however only oestrogen receptor, progesterone receptor and HER2 are currently used to tailor the therapy of breast cancer patients (Goldhirsch et al, 2005). The use of expression arrays to derive molecular profiles that are predictive of clinical outcome has received great attention in the last 5 years (van't Veer et al, 2005; Reis-Filho et al, 2006b), especially in the neoadjuvant setting (Davidson and Morrow, 2005). Predictive signatures for different neoadjuvant chemotherapy regimens have

*Correspondence: Professor M Dowsett, Academic Department of Biochemistry, The Royal Marsden NHS Trust, Fulham Road, London, SW3 6JJ, UK; E-mail: Mitch.Dowsett@icr.ac.uk

${ }^{6}$ Current address: Department of Oncology, St Mary's Hospital, London, UK

${ }^{7}$ Current address: Molecular and Cellular Pathology, University of Queensland, Queensland Institute of Medical Research, Brisbane, Australia

Received 21 July 2006; revised 12 October 2006; accepted 23 October 2006; published online 28 November 2006 been reported by some investigators but with less success by others (Chang et al, 2003; Ayers et al, 2004; Cleator and Ashworth, 2004; Chang et al, 2005a; Hannemann et al, 2005; Iwao-Koizumi et al, 2005; Modlich et al, 2005; Rouzier et al, 2005; Dressman et al, 2006; Reis-Filho et al, 2006b). Although some of these results are promising, issues related to the instability of mRNA, experimental design and data analysis have led many to call into question the validity of current approaches (Ransohoff, 2004; Brenton et al, 2005; Ioannidis, 2005; Reis-Filho et al, 2006b).

Chromosomal comparative genomic hybridisation (cCGH) has been widely used to analyse the pattern of unbalanced genomic aberrations in breast cancer (Roylance et al, 1999; Buerger et al, 1999a, b; Albertson, 2003; O'Connell, 2003; Reis-Filho et al, 2005a). More recent studies have employed higher resolution array-based CGH (aCGH) showing the enormous complexity of breast cancer genomes. Nonetheless, these studies have consistently reported the same regions of gain $(1 \mathrm{q}, 8 \mathrm{q}, 11 \mathrm{q}, 17 \mathrm{q}, 20 \mathrm{q})$ and loss $(8 \mathrm{p}, 9 \mathrm{p}, 13 \mathrm{q}$, 16q) (Rennstam et al, 2003; Loo et al, 2004; Naylor et al, 2005; Nessling et al, 2005). Unbalanced chromosomal aberrations and changes in gene copy numbers have been reported as a mechanism for acquired drug resistance to chemotherapy in cell line studies (Leyland-Jones et al, 1999; Yasui et al, 2004). However, no genome-wide analysis addressing response prediction by aCGH in breast cancer patients has been published. 
The primary aim of this study was to determine whether aCGH could be used to identify unbalanced genomic changes predictive of response to preoperative doxorubicin and cyclophosphamide (AC) combination. We also sought to investigate the hypotheses that resistance to chemotherapy could be driven either by selection of chemotherapy resistant populations of neoplastic cells or by the induction of specific genomic aberrations.

\section{MATERIALS AND METHODS}

\section{Patients and samples}

Patients were recruited and treated at the Royal Marsden Hospital (Sutton and London, UK). Eligible patients were those undergoing neoadjuvant adriamycin and AC chemotherapy treatment at doses of 60 and $600 \mathrm{mg} \mathrm{m}^{-2}$, respectively, three weekly, for a clinically measurable breast cancer. Approval by the Royal Marsden Hospital Clinical Research and Ethics committees was granted and written consent was obtained in all cases. Patients were offered neoadjuvant treatment for one of several standard indications including locally advanced or inflammatory breast cancer, high tumour to breast size ratio and tumours located close to the nipple. The majority of the patients were from a previously published study on RNA expression profiling (Cleator et al, 2006).

Diagnosis was confirmed on core-cut biopsies subjected to routine histological analysis. Patients who demonstrated at least a partial clinical response received six cycles of treatment before local treatment. Patients with no or only marginal response after three or four cycles, proceeded directly to local treatment or were commenced on alternative systemic treatment (docetaxel).

Clinical size of tumour was recorded as the largest diameter and a diameter perpendicular to this. This was recorded before commencement and at completion of treatment. Clinical response was categorised as follows: no palpable abnormality after treatment, complete clinical response (cCR); $>50 \%$ reduction in the product of the bidimensional measurements, partial response $(\mathrm{PR}) ;<50 \%$ reduction in the product of bidimensional measurements was recorded as no change (NC); residual ill-defined thickening after a good response, minimal residual disease (MRD) (Cleator et al, 2006). No patients in the study demonstrated progressive disease, an increase of more than $25 \%$ in the product of bidimensional measurements. Those cases in which there was no residual invasive carcinoma at surgery were classified as a complete pathological response (pCR). Good responders were defined as PCR, cCR, MRD; poor responders were defined as PR or NC. Eight patients undergoing a complete clinical and radiological (on ultrasound) response received radiation only as local treatment. Therefore some of the cCRs may represent undocumented pCRs.

Research 14-gauge core biopsies were collected before commencing treatment and again at 21 days after first treatment. Samples were snap frozen in liquid nitrogen. All samples were thereafter coded using a study number as an identifier. Frozen cores were embedded in optimum cutting temperature embedding compound and sectioned at $-20^{\circ} \mathrm{C}$ in a cryostat. Sections ( $5 \mu \mathrm{m}$ thickness) were taken for hematoxylin and eosin staining to assess histological character superficially from the core as soon as 'fullface' was reached. The percentage of cells comprising invasive malignant disease was recorded. For patients in whom multiple biopsies were available, that with the highest invasive content was used for microarray analysis. Samples with less than $20 \%$ invasive cancer content were excluded from the study. Eight micrometer thick, nuclear fast red-stained representative frozen sections from 44 patients with primary breast cancer obtained before a neoadjuvant combination of $\mathrm{AC}$ were microdissected. In 22 patients consent for a second research core needle biopsy was granted and the procedure was technically feasible; in 17 of these, samples obtained 3 weeks after first course of chemotherapy (before cycle two) contained proportions of neoplastic cells suitable for microdissection (i.e. $>20 \%$ of neoplastic cells). Twenty-one surgical formalin-fixed paraffin-embedded resection samples taken after 4-6 cycles of AC and with sufficient amounts of residual neoplastic cells were retrieved from the pathology files of the Royal Marsden Hospital.

\section{Fluorescent in situ hybridisation}

Fluorescent in situ hybridisation (FISH) analysis was performed on representative $4-\mu \mathrm{m}$ sections using PathVysion HER-2 DNA probe mixture containing a HER-2 DNA probe $(190 \mathrm{~kb}$ Spectrum Orange directly labelled DNA probe) and the CEP 17 DNA probe (5.4 kb Spectrum Green directly labelled fluorescent DNA probe specific for the chromosome $17 \alpha$-satellite DNA sequence) as described previously (Dowsett et al, 2003). A total of 60 cells were scored for red and green signals for each section and results were expressed as a ratio of red to green signals, with a ratio $\geqslant 2.0$ being considered amplified (Dowsett et al, 2003).

\section{Microdissection and DNA extraction}

Frozen and formalin-fixed samples were subjected to aCGH analysis after microdissection of neoplastic cells with a sterile needle under a stereomicroscope (Olympus SZ61) from one to three consecutive $8 \mu \mathrm{m}$ nuclear fast red-stained sections (median $=1)$. Estimated purity of tumour cells ranged from 75 to $100 \%$ (median $=90 \%$ ) (Supplementary Figure 1 ). DNA was extracted according to standard methods (Reis-Filho et al, 2005b). The DNA yield and purity was assessed by spectrophotometry and the DNA quality (DNA fragment size range) by agarose gel electrophoresis as described previously (Reis-Filho et al, 2005b).

\section{Microarray-based comparative genomic hybridisation}

Microarray-based CGH was performed with in-house produced microarrays containing $\sim 5.8 \mathrm{~K}$ bacterial artificial chromosome (BAC) clones, spaced out throughout the genome in $\sim 0.9 \mathrm{Mb}$ intervals. The Breakthrough Breast Cancer Research Centre CGH microarray is composed of the same BAC clones as described by Reis-Filho et al (2005b).

Mapping of the BAC clones was retrieved from public sources and positioned according to the May 2004 build of the human genome sequence (hg17). When genomic positioning was dubious or conflicting, BAC end pair sequencing and FISH mapping was performed. Clones that either (i) showed poor quality end sequences or (ii) hybridised to multiple chromosomal locations or to a cytogenetic location inconsistent with their position in the sequence assembly were excluded from analysis. Bacterial artificial chromosome clones were spotted in triplicate onto Corning GAPSII-coated glass slides (Corning, NY, USA). Labelling of $250 \mathrm{ng}$ of non-amplified DNA obtained from microdissected frozen sections or $1000 \mathrm{ng}$ of DNA retrieved from microdissected formalin-fixed paraffin-embedded tissue sections, hybridisation and washes were carried out essentially as described previously (Reis-Filho et al, 2005b, 2006a; Natrajan et al, 2006).

Arrays were scanned with a GenePix 4000A scanner (Axon Instruments Inc., Union City, CA, USA); fluorescence data were processed with GenePix 4.1 image analysis software (Axon Instruments Inc.) as described previously (Reis-Filho et al, 2005b, 2006a; Natrajan et al, 2006).

\section{Data analysis}

The $\log _{2}$ ratios were normalised for spatial and intensitydependent biases using a two-dimensional Loess local regression. Experiment replicates ('dye-swaps') were collated, BAC clone 
replicate spots averaged, and clones excluded with poor reproducibility between replicates (s.d. $>0.2$ ). Samples with $>70 \%$ missing/poor values were excluded, as were clones with missing/ poor values in $>70 \%$ samples. Missing data were imputed by k-nearest neighbours (Troyanskaya et al, 2001) and clones with no mapping information (May 2004 build of the human genome sequence, hg17) were excluded. A total of 5001 different BAC clones were used in the final analysis.

\section{Statistical analysis}

All data transformation and statistical analysis were carried out in $\mathrm{R}$ 2.0.1 (http://www.r-project.org/), BioConductor 1.5 (http:// www.bioconductor.org/), making extensive use of modified versions of the package aCGH in particular (Paris et al, 2004; Natrajan et al, 2006) and S-Plus (version 6.2.1). The $\log _{2}$ ratio of each BAC clone in each tumour sample was centred by the median of each case. Thresholds for determining copy number gains and losses were determined as exceeding $\pm 3.0 \times$ s.d. of the mean of these control experiments $\left(\log _{2}\right.$ ratio of \pm 1$)$. For identification of DNA copy number alterations, data were smoothed using a local polynomial adaptive weights smoothing procedure for regression problems with additive errors (Hupe et al, 2004; Natrajan et al, 2006).

Associations between genomic loci were assessed by calculating Pearson's correlations between thresholded values for each clone, assigned as 1,0 or -1 for gain, $\mathrm{NC}$, or loss in copy number. Thresholded data for each clone were also used for categorical analysis using a Fisher's exact test adjusted for multiple-testing with a correction for multiple testing using the step-down permutation procedure maxT, providing strong control of the family-wise type I error rate.

\section{RESULTS}

\section{Patient, tumour and biopsy characteristics}

A total of 44 patients were included in the study. Patient and tumour characteristics are summarised in Table 1 according to clinical response. Median tumour diameter was $4 \mathrm{~cm}$ (range 2-10). Two patients had inflammatory breast cancer (T4d). Median follow-up was 24 months (range, 9-38 months).

Of the 44 patients, 24 (55\%) demonstrated a 'good' and $20(45 \%)$ a 'poor' clinical response. Four patients (9\%) were documented as undergoing a pathological Complete Response (pCR), 17 (37\%) underwent a cCR and three (7\%) had ill-defined thickening (MRD) at end of treatment; eight (19\%) had a PR and $12(28 \%)$ showed NC.

\section{Validation of aCGH method}

DNA was extracted from 61 frozen samples. The median DNA yield obtained per sample was $660 \mathrm{ng}$ (range 152-3188 ng). Owing to constraints in amount of tumour material available from frozen core biopsies after manual dissection, we assessed the reproducibility and quality of profiles obtained with 250,500 and $1000 \mathrm{ng}$ of tumour DNA. All DNA concentrations showed optimal results, with the Pearson's coefficient of correlation ranging from 0.93 to 0.96 (data not shown). Biological replicates of aCGH experiments also demonstrated high reproducibility: two independent research core biopsies were obtained before neoadjuvant chemotherapy for five patients. DNA extraction and CGH arrays were performed separately for these paired samples. For each of the matched pairs, the Pearson's correlation coefficient ranged from 0.64 to 0.86 (mean 0.78 , data not shown). In six cases, HER2 amplification was defined by aCGH. Fluorescent in situ hybridisation analysis confirmed the results in all cases, providing further evidence to
Table I Patient and tumour characteristics

\begin{tabular}{|c|c|c|c|}
\hline Patients & $\begin{array}{l}\text { Responders } \\
(n=24)\end{array}$ & $\begin{array}{c}\text { Non-responders } \\
(n=20)\end{array}$ & $P$-value \\
\hline \multicolumn{4}{|l|}{ Patient age } \\
\hline$\leqslant 40$ & 5 & 2 & $0.57^{*}$ \\
\hline$>40$ & 19 & 18 & \\
\hline \multicolumn{4}{|l|}{ Menopausal status } \\
\hline Post & 12 & 6 & $0.22 *$ \\
\hline Pre & 12 & 13 & \\
\hline & & I unavailable & \\
\hline \multicolumn{4}{|l|}{ Tumour size } \\
\hline $\mathrm{T} 2$ & 15 & 10 & $0.40 *$ \\
\hline $\mathrm{T} 3 / \mathrm{T} 4$ & 9 & 10 & \\
\hline \multicolumn{4}{|l|}{ Nodal status } \\
\hline NO & 15 & 14 & $0.60 *$ \\
\hline $\mathrm{NI} / \mathrm{N} 2 / \mathrm{N} 3$ & 9 & 6 & \\
\hline \multicolumn{4}{|l|}{ HER2 - IHC } \\
\hline Negative & 17 & 19 & $0.03 *$ \\
\hline Positive & 7 & I & \\
\hline \multicolumn{4}{|l|}{ HER2 - FISH } \\
\hline Negative & 19 & 18 & $0.28^{*}$ \\
\hline Positive & 5 & 1 & \\
\hline & & I unavailable & \\
\hline \multicolumn{4}{|c|}{ Lympho-vascular invasion } \\
\hline Absent & 19 & 10 & $0.04 *$ \\
\hline Present & 5 & 10 & \\
\hline \multicolumn{4}{|l|}{ Histological type } \\
\hline Invasive ductal & 19 & 18 & $0.39 * *$ \\
\hline Lobular & 5 & 2 & \\
\hline Medullary & 1 & 0 & \\
\hline Metaplastic & 0 & । & \\
\hline \multicolumn{4}{|l|}{ Histological grade } \\
\hline 100 & 0 & 0 & \\
\hline$\|$ & 8 & 10 & $0.26 * *$ \\
\hline III & 16 & 10 & \\
\hline \multicolumn{4}{|l|}{ Oestrogen receptor } \\
\hline Negative & 8 & 7 & $0.6 *$ \\
\hline Positive & 16 & 13 & \\
\hline
\end{tabular}

$\mathrm{FISH}=$ fluorescent in situ hybridisation. *: Fisher's exact test; *** $\chi^{2}$ test.

support the validity of the aCGH analysis methods employed in this study (data not shown).

For six cases, high-resolution cCGH was performed and the genetic profiles compared with those obtained with aCGH. Correlation was good-to-excellent, with correlations for low-level gains and deletions $>20 \mathrm{Mb}$ and any amplification ranging from 60 to $87.5 \%$ ( median $=79.5 \%$, mean $=77.8 \%$, data not shown). However, aCGH was more sensitive in detecting small losses and low-level gains than HR-CGH.

\section{Genomic alterations in 44 pre-chemotherapy breast cancer samples}

To identify genomic regions harbouring recurrent unbalanced genomic changes, we plotted the frequency of tumours showing gain or loss for each BAC across the genome (Figure 1A). The most frequent $(>30 \%)$ genomic changes (Table 2) comprised gains of $1 \mathrm{q}(66 \%), 5 \mathrm{p}(32 \%), 8 \mathrm{q}(70 \%), 16 \mathrm{p}(36 \%)$ and $20 \mathrm{q}(41 \%)$ with the smallest regions of genomic gain on $1 \mathrm{q} 31.1-1 \mathrm{q} 31.2$ and $1 \mathrm{q} 22-$ 1q25.3, 5p15.31-5p15.33, 8q23.1-8q25.1, 16p11.2-16p12.2 and 
A

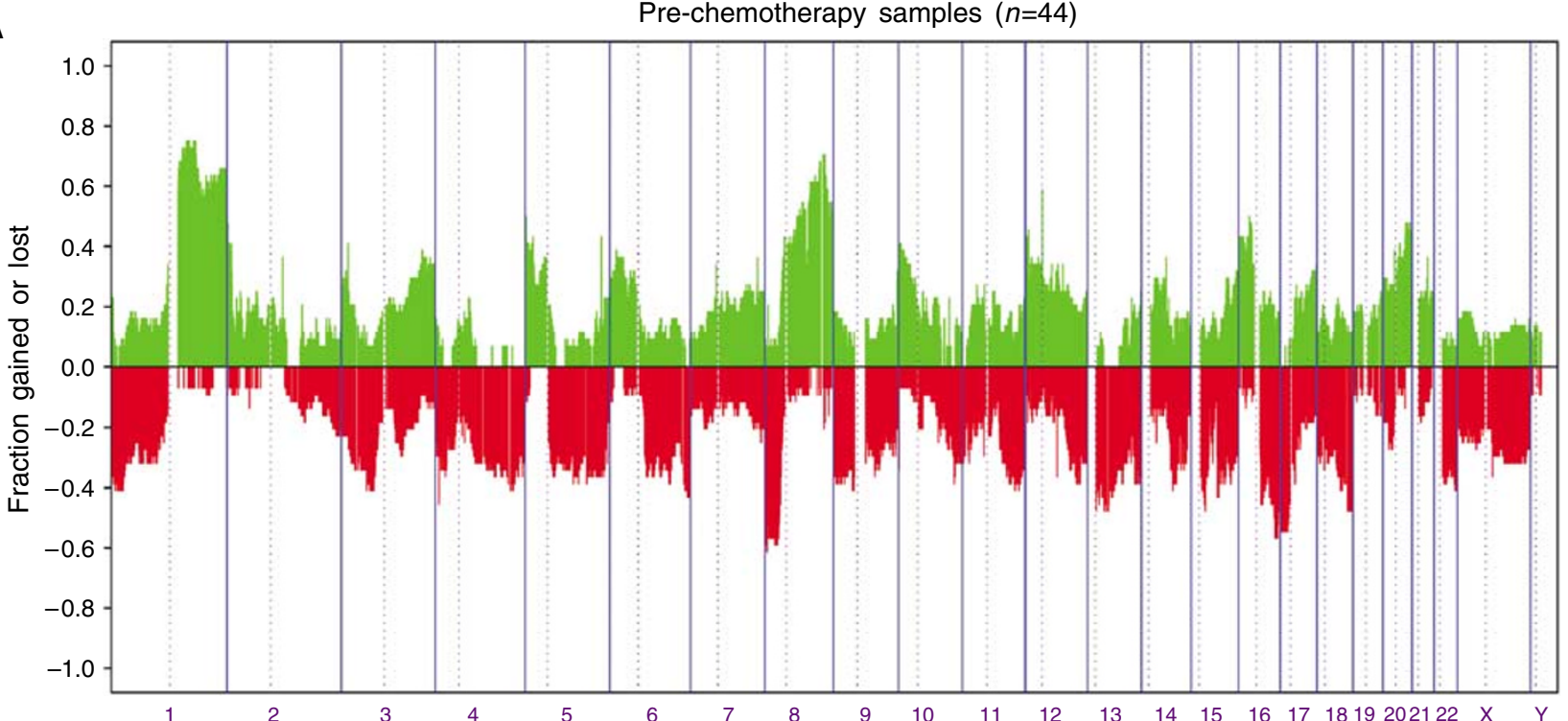

B

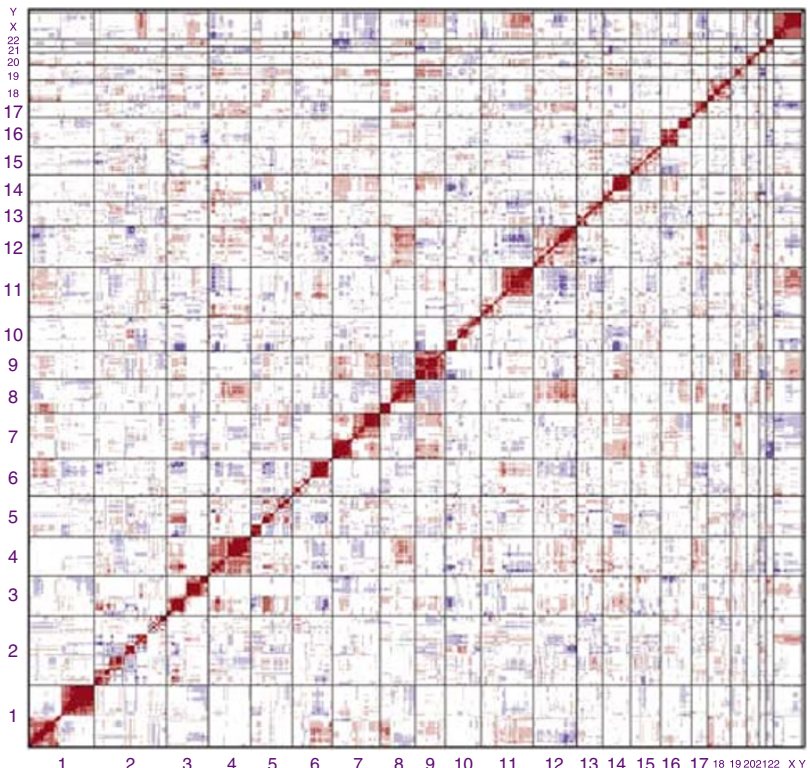

C

Figure I Frequency of copy number changes in 44 invasive breast carcinomas. (A) Overall frequency of DNA copy number alterations found in 44 invasive breast carcinomas as defined by aCGH. The proportion of tumours in which each clone is gained (green bars) or lost (red bars) is plotted (y axis) for each BAC clone according to genomic location (x axis). Vertical dotted lines represent chromosome centromeres. (B) - Pearson's correlation matrix of all thresholded aCGH data for 29 ER-positive, invasive breast carcinomas. Strong positive correlations are plotted as dark red, strong negative correlations as dark blue. Note the associations between chromosomes Ip/8p, Ip/I2q, 4q/8p, 7p/22, 8q/I2q and I lq/I2q. Bacterial artificial chromosome clones are plotted in genome order. (C) Pearson's correlation matrix of all thresholded aCGH data for I5 ER-negative, invasive breast carcinomas. Strong direct plotted as dark red, strong negative correlations as dark blue. Note the associations between chromosomes Ip and $7 q, 16 p$ and $17 q$, and strong inverse

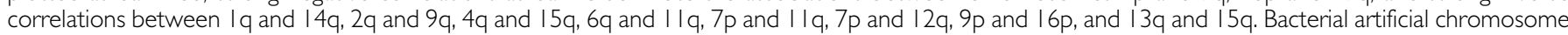
clones are plotted in genome order.

$20 \mathrm{q} 13.13-20 \mathrm{q} 13.33$, respectively. Losses were observed on $4 \mathrm{q}$ (39\%), 8p (50\%), 9p (36\%), 11q (32\%), 13q (36\%), 16q (52\%) $17 \mathrm{p}$ $(50 \%)$ and $18 \mathrm{q}(39 \%)$ with the smallest regions of deletion on 4q32.3-4q33, 8p21.1-p23.3, 9p22.2-9p24.3, 11q23.1-11q25, $13 \mathrm{q} 14.11-13 \mathrm{q} 14.3,16 \mathrm{q} 23.1-\mathrm{q} 24.3,17 \mathrm{p} 12-17 \mathrm{p} 13.3$ and $18 \mathrm{q} 22.1-$ $\mathrm{q} 23$. In addition to the large regional alterations, the resolution of the $\mathrm{BAC}$ array allowed us to map smaller regions of gain or loss. Bacterial artificial chromosome clones gained or deleted in $>30 \%$ of the tumours are described in Supplementary Tables 1 and 2, respectively.

\section{Comparison of genomic alterations in different phenotypes of breast cancer}

On the basis of three distinguishing phenotypic characteristics (ER, HER2 and histological type), we characterised genetic alterations that might be associated with subtypes of breast cancer on the 44 pretreatment biopsies. Oestrogen receptor (ER)-negative tumours $(N=15)$ were characterised by significantly more chromosomal changes than ER-positive tumours (Table 3 and Supplementary Figure 2). Subgroup analysis showed that the 
Table 2 Recurrent gains and losses of genomic material in $>30 \%$ of the samples

\begin{tabular}{|c|c|c|c|c|c|}
\hline Gain region & $\begin{array}{l}\text { Start } \\
\text { (Mb) }\end{array}$ & $\begin{array}{l}\text { End } \\
(\mathrm{Mb})\end{array}$ & Loss region & $\begin{array}{l}\text { Start } \\
\text { (Mb) }\end{array}$ & $\begin{array}{l}\text { End } \\
\text { (Mb) }\end{array}$ \\
\hline$|p| 2-q t e \mid$ & 119.8 & 245.2 & $|p 3| . \mid$ & 75.3 & 78.3 \\
\hline $2 \mathrm{p} 25.3-\mathrm{p} 25.1$ & 0.1 & 8.9 & $|p 3| .|-p 2| .3$ & 79.2 & 97.8 \\
\hline $3 \mathrm{q} 26.1-\mathrm{q} 29$ & 163.8 & 198.3 & $|p 32|-.p 3||$. & 58.7 & 69.1 \\
\hline $5 p|3.3-p| 2$ & 31.9 & 44.9 & Ip36.33-p34.2 & 1 & 42.9 \\
\hline $5 p|5.33-p| 4.3$ & 0.4 & 20.6 & $3 p 24.3-p / 3$ & 20.2 & 74.2 \\
\hline $6 p|2.3-p| 2.1$ & 49.6 & 53.5 & $4 p|5.3|-p \mid 5.2$ & 18 & 26.6 \\
\hline $6 p 24.3-p 22.1$ & 7.3 & 31.2 & 4p|6.1-p|5.33 & 7.2 & 15.4 \\
\hline $7 q 34-q 35$ & 142.2 & 144.8 & $4 q 21.23-q 35.2$ & 85.1 & 190.9 \\
\hline $8 p 12$ & 36.8 & 37.9 & $5 q|1.2-q| 3.2$ & 54.7 & 71 \\
\hline $8 p 12-q$ tel & 38.3 & 44.9 & $5 q \mid 3.2-q 35.1$ & 72.4 & 170.2 \\
\hline |Op|5.3 & 0.1 & 1.2 & $6 q 13-q \mid 6.2$ & 74.5 & 99.7 \\
\hline $10 p|5.3-p| 2.1$ & 2.2 & 27.8 & $6 \mathrm{q} 21-23.2$ & 105.8 & 131.9 \\
\hline$|2 p||.22-q| \mid$ & 29.5 & 36.9 & 6q25.1 -qtel & 151.7 & 170.4 \\
\hline$|2 p| 2.1-p|| .22$ & 21.3 & 29.3 & $8 p 23.3-p 12$ & 0.3 & 36.7 \\
\hline$|2 p| 3.2-p|2|$. & 9.8 & 21.3 & $9 p 24.3-q 21.1$ & 0.1 & 68.5 \\
\hline$|2 p| 3.33-p|3.3|$ & 0.1 & 8.1 & $9 \mathrm{q} 22.2-\mathrm{q} 31.1$ & 87.4 & 99.8 \\
\hline $12 \mathrm{q}|3.3-\mathrm{q}| 4.1$ & 56.5 & 58.3 & $10 p \mid 5.3$ & 0.9 & 1.2 \\
\hline $12 q 15-q 21.1$ & 67.6 & 71.2 & I0q25.3-gtel & $1 \mid 8.4$ & |35.| | | | \\
\hline $12 \mathrm{q} 24.3-\mathrm{q} 25.1$ & 67.1 & 71.8 & $1 \mid \mathrm{p} 15.2$ & 14.8 & 15.2 \\
\hline |2q25. | -qtel & 73 & 78.2 & ||$q|4.2-q| 4.3$ & 86.4 & 88.9 \\
\hline $15 q 26.2-q 26.3$ & 96.3 & 97.7 & | |q|4.3-qtel & 91.9 & 133.7 \\
\hline$|6 p| 3.3-p|| .2$ & 0.9 & 32.9 & $12 \mathrm{q} 22-\mathrm{q} 24.23$ & 94.9 & 118.2 \\
\hline $20 \mathrm{p} 11.21$ & 23.3 & 26.2 & |2q24.31 -qtel & 121.6 & 132.2 \\
\hline \multirow[t]{20}{*}{$20 q|1.21-q| 3.33$} & 30 & 62.4 & $13 q 12.11-q 31.1$ & 18.3 & 85.2 \\
\hline & & & | 3q33. I -qtel & 100.2 & $1 \mid 4.1$ \\
\hline & & & $14 q 23.3-q 24.3$ & 63.1 & 76.9 \\
\hline & & & $14 q 31.1-q 32.11$ & 79.5 & 87.9 \\
\hline & & & $14 q 32.12$ & 90.8 & 91.4 \\
\hline & & & $|5 q| 1.2-q \mid 4$ & 20.5 & 33.3 \\
\hline & & & $15 q 14$ & 33.4 & 37.5 \\
\hline & & & $15 q 21.3-q 24.3$ & 55.1 & 75.5 \\
\hline & & & $15 \mathrm{q} 25.1$ & 78.6 & 79.3 \\
\hline & & & $15 q 25.2-q 26.1$ & 81.6 & 89.6 \\
\hline & & & $15 q 26.1-q 26.2$ & 91.4 & 94.6 \\
\hline & & & | 5q26.3-qtel & 97.9 & 99.9 \\
\hline & & & $|6 q| 2.1$-qtel & 46.4 & 88.5 \\
\hline & & & $|7 p| 3.3-q \mid 1.2$ & I.1 & 34.1 \\
\hline & & & $|8 p||.31-p| \mid .23$ & 6.1 & 7.6 \\
\hline & & & $|8 q| 1.2-q \mid 2.1$ & 20.6 & 25.6 \\
\hline & & & $|8 \mathrm{q}| 2.3-\mathrm{qtel}$ & 40.6 & 75 \\
\hline & & & $19 \mathrm{q}|3.31-\mathrm{q}| 3.32$ & 48.9 & 50.1 \\
\hline & & & $22 \mathrm{q}|\mathrm{l} .21-\mathrm{q}| 3.33$ & 17.3 & 49.2 \\
\hline & & & $23 q 22.1-q 28$ & 98.6 & 146.7 \\
\hline
\end{tabular}

following chromosomal changes were more frequently associated with ER negativity: gains on $1 \mathrm{p}, 2 \mathrm{p}, 2 \mathrm{q}, 6 \mathrm{q}, 7 \mathrm{q}, 9 \mathrm{p}, 11 \mathrm{q}$ and $19 \mathrm{q}$ with large regions on $1 \mathrm{p} 31-1 \mathrm{p} 34.2,7 \mathrm{q} 32-7 \mathrm{q} 36$ and losses on $4 \mathrm{p}$, $4 q, 5 p, 5 q, 12 q$ and $17 q$ as well as large regions such as the whole long arm of chromosome 5 and whole chromosome 4 .

Pearson's correlation analysis of the subset of ER-positive tumours $(n=29)$ revealed chromosomal alterations that coexist in this group of tumours. The heat map in Figure 1B shows regions of positive (change in same direction: red) and negative (change in opposite direction: blue) correlations. Relatively large regions of correlation were seen between changes in copy number of BACs on chromosome $1 \mathrm{p}$ and $8 \mathrm{p}(P<0.01), 3 \mathrm{p}$ and $4 \mathrm{p}(P<0.001), 4 \mathrm{q}$ and $8 \mathrm{q}$ $(P<0.01)$ and $8 \mathrm{q}$ and $12 \mathrm{q}(P<0.01)$ were observed, as were strong inverse correlations between $1 \mathrm{p}$ and $12 \mathrm{q}(P<0.0005), 7 \mathrm{p}$ and 22 $(P<0.001)$ and $11 \mathrm{q}$ and $12 \mathrm{q}(P<0.001)$ (Figure $1 \mathrm{~B})$. Pearson's correlation matrix of ER-negative tumours revealed strong direct associations between $1 \mathrm{p}$ and $7 \mathrm{q} \quad(P<0.001), 16 \mathrm{p}$ and $17 \mathrm{q}$ $(P<0.001)$, and strong inverse correlations between $1 \mathrm{q}$ and $14 \mathrm{q}$ $(P<0.005), 2 \mathrm{q}$ and $9 \mathrm{q}(P<0.001), 4 \mathrm{q}$ and $15 \mathrm{q}(P<0.001), 6 \mathrm{q}$ and $11 \mathrm{q}(P<0.001), 7 \mathrm{p}$ and $11 \mathrm{q}(P<0.001), 7 \mathrm{p}$ and $12 \mathrm{q}(P<0.01), 9 \mathrm{p}$ and $16 \mathrm{p}(P<0.001)$ and $13 \mathrm{q}$ and $15 \mathrm{q}(P<0.005)$ (Figure $1 \mathrm{C})$.
Comparing invasive lobular carcinomas $(n=7)$ with non-lobular cases (37 cases), 16q loss (from 16q12.1 to 16q24.3) was significantly associated with lobular phenotype (unadjusted Fisher's exact test $<0.01$ ) (Supplementary Table 3 and Supplementary Figure 3). This region contains a number of cadherin genes (CDH1, CDH3, CDH5, $\mathrm{CDH} 8, \mathrm{CDH} 11)$. Gain of $8 \mathrm{q} 21.11-\mathrm{q} 24.23$ was significantly associated with the ductal phenotype (Supplementary Table 3 and Supplementary Figure 3).

Comparison between the six cases with HER2 amplification on 17q11.2 with the 38 HER2-negative cases revealed more frequent gains of 6 p25.2-p24.2, 17q12 and Xp22.33-p11.36, and loss of 18p11.31 (Supplementary Table 3 and Supplementary Figure 4). On the other hand, loss of 16q23.3-q24.1 was more frequently observed in HER2 - tumours. This would be expected given that all HER2 + cases were of histological grade III and loss of $16 \mathrm{q}$ is significantly less frequently found in this group of tumours (ReisFilho et al, 2005a; Simpson et al, 2005).

\section{Prediction of tumour response}

Comparison of the molecular genetic profiles of objective clinical responders (complete and partial clinical responders, $N=24$ ) with those of non-responders revealed loss of a $13.3 \mathrm{Mb}$ region on $13 q 31.1-13 q 32.2$ to be the only significant difference (Figure 2). This region includes the genes SLITRK6, SLITRK5, GPC5, GPC6, DCT, TGDS, SOX21, ABCC4, CLDN10, DZIP1, DNAJC3, UGCGL2, HS6ST3, HSP90AB6P, OXGR1, MBNL2 and RAP2A. In addition, this region also encompasses the micro RNA cluster miR-17-92, which is reported to induce tumour cell growth and to be overexpressed and sometimes amplified in aggressive forms of lung cancer (Hayashita et al, 2005).

\section{Comparison of pre-chemotherapy samples to D21 samples, before cycle two of $\mathrm{AC}$}

Unsupervised hierarchical clustering analysis based upon genetic alterations on all chromosomes showed that all pre- and D21 postbiopsies clustered together ( $N=17$ cases) (Figure $3 \mathrm{~A})$. There were no significant differences in the profiles between poor (10 cases) and good responders (seven cases) $(P=0.95$, KolmogorovSmirnov test). The comparison of the pattern and frequency of unbalanced genomic changes detected by aCGH analysis in matched pretreatment and D21 biopsies revealed no significant differences (multi-Fisher's exact test, data not shown).

\section{Comparison of pre-chemotherapy samples to surgical samples, after $4-6$ cycles of $\mathrm{AC}$}

Twenty-one surgical samples out of 44 cases were available (48\%). All but three segregated with the respective pre-chemotherapy sample by unsupervised hierarchical clustering (Figure 3B). For 12 cases, pre-, D21 and at surgery samples were available. Unsupervised hierarchical clustering analysis based upon genetic alterations on all chromosomes was performed. All 12 'triplicates' clustered together.

Comparison between the genomic profiles obtained with DNA extracted from matched frozen and formalin-fixed pretreatment core biopsies were performed $(n=2)$. The profiles showed a good concordance $\left(r^{2}>0.8\right)$. Subsequently, a comparison of the aCGH profiles of 21-matched pretreatment core biopsies and the respective excision specimens obtained after 4 months of neoadjuvant chemotherapy revealed the presence of gains of 4q13.1 (9/21, 43\%), 11p15.2-p15.5 (14/21, 66\%), 12q13.3 (14/21, $66 \%), 18 p 11.21(12 / 21,52 \%)$ and $19 q 13.2(12 / 2152 \%)$ in the excision specimens (Figure 4 and Supplementary Table 4). After FDR adjustment, only the gain on $11 \mathrm{p} 15.2-\mathrm{p} 15.5$ retained its statistical significance. Although we cannot completely rule out that this change could result from the comparison between DNA 
Table 3 Copy number changes significantly more prevalent in ER-negative compared to ER-positive tumours

\section{ER negative vs}

ER positive

Start End Genes (regions $<15 \mathrm{Mb}$ )

Gain

|p21.1-p|3.|

Ip31.3-p21.3

Ip34.3-p32.3

$2 p|| .2-q|| .2$

$2 p|6.1-p| 4$

2p25.3-p25. I

2q24. 1

6q23.2

$7 q 32.3-q 33$

7q34-qtel

$8 q 11.21$

$9 p 24.1-p 22.2$

| | q24. I-qtel

$12 \mathrm{q} 13.13$

19p|3.|1

19.2

$19 q 13.2$

44. 1

$|9 q| 3.2-q|3.3|$

45.2
BCLI IA, PAPOLG, REL, PEXI3, AHSA2, USP34, XPOI, CCT4, COMMDI, B3GNTI, TMEMI7, EHBPI, OTXI, MDHI, UGP2, VPS54, PELII, AFTIN, SERTAD2, SLCIA4, CEP68, RAB IA, ACTR2, SPRED2

12

159.7 ACVRIC, ACVRI, UPP2, PKP4, TANCI

$131.3 \quad 134.9$

AKAP7, ARGI, CRSP3, ENPP3, OR2A4, CTAGE4, ENPPI, CTGF, MOXDI, STX7, TAAR9, TAAR8, TAAR6, TAAR5, TAAR2, TAARI, VNNI, VNN3, VNN2, RPS I2, EYA4, TCF2I, TBPLI, SLC2A I2, SGK

134 PLXNA4B, CHCHD3, EXOC4, SLC35B4, AKRIBI, AKRIBIO, BPGM

158

51.4 MCM4, UBE2V2, EFCABI, SNAI2

18

133.7

52.8

POU6FI, DAZAP2, BIN2, ELAI, GALNT6, SLC4A8, SCN8A, ACVRIB, ANKRD33, ACVRLI, GRASP, NR4AI, KRT7, KRTHBI, KRTHB6, KRTHB3, KRTHB5, KRTHB4, KRTHB2, KRT6B, KRT6E, KRT6A, KRT5, KRT2A, KRTI, KRTIB, K22O, KRT3, KRT4, KRT8, KRTI 8, EIF4B, TENCI, SPRYD3, IGFBP6, SOAT2, CSAD, ZNF740, ITGB7, RARG, MFSD5, ESPLI, PFDN5, MYGI, AAAS, SP7, SPI, AMHR2, PCBP2, MAP3K I2, TARBP2, NPFF, ATF7, ATP5G2, CALCOCOI, HOXCI3, HOXCI2, HOXCII, HOXCIO, HOXC9, HOXC8, HOXC6, HOXC5, HOXC4

21.3 TM6SF2, GATAD2A, SF4, TSSK6, NDUFA I3, CILP2, PBX4, EDG4, GMIP, ATPI 3A I, ZNFI0I, ZNFI4, ZNF506, ZNF56, ZNF93, ZNF682, ZNF90, ENH5, ZNF486, ENTI, ZNF626, ZNF85, ZNF430, ZNF7I4, ZNF431, ZNF708

44.9 MRPS I 2, FBXO I7, FBXO27, PAK4, IL28B, IL28A, IL29, LRFNI, GMFG, SAMD4B, PAFI, IXL, ZFP36, PLEKHG2, RPSI6, SUPT5H, TIMM50, DLL3, SELV, LGALSI3, LGALS/4

48.8 MAP3KIO, TTC9B, AKT2, PLD3, HIPK4, PRX, SERTADI, SERTAD3, BLVRB, SPTBN4, SHKBPI, LTBP4, NUMBL, ADCK4, ITPKC, SNRPA, RAB4B, EGLN2, CYP2A7, CYP2B, CYP2B6, CYP2GIP, CYP2AI3, CYP2FI, CYP2SI, AXL, HNRPULI, TGFBI, BCKDHA EXOSC5, CEACAM2I, CEACAM4, CEACAM7, CEACAM5, CEACAM6, CEACAM3, LYPD4, DMRTC2, RPS I9, CD79A, ARHGEFI, RABACI, ATPIA3, GRIK5, ZNF574, POU2F2, DEDD2, ZNF526, GSK3A, ERF, CIC, PAFAHIB3, EGFL4, CNFN, LIPE, CEACAMI, CEACAM8, PSG3, PSG8, PSGI, PSG6, PSG4, PSGII, PSG5, PSG9, TEXI0I, LYPD3, PHLDB3, ETHEI, ZNF575, XRCCI, IRGQ, ZNF576

Loss

$\begin{array}{lrc}\text { 4p|5.32-p|5.2 } & 16.9 & 26.6 \\ \text { 4p|5.33-p|5.32 } & 8.8 & 15.4 \\ & & \\ 4 p|6.3-| 6.1 & 3.5 & 8.6 \\ 4 q 24-q 34.3 & 106.7 & \mid 78.4 \\ 4 q 35 . \mid-q 35.2 & \mid 86.4 & 188.8 \\ 5 p \mid 5.33 & 2.8 & 5 \\ 5 q|1 .|-q \mid 3.2 & 50.1 & 7 \mid \\ 5 q|3.2-q| 4.3 & 72.4 & 85.5\end{array}$

\section{$5 q 15$}

$5 q 22.1-q 23.3$

$5 q 23.3-q 33.1$

$5 q 33.1-q 35.2$

$12 q 13.11$

$12 q|3.12-q| 3.13$

92.7

92.7
110.9

132.2

150.2

44.7

46.3

\section{6}

QDPR, LAP3, MED28, CND3, SLIT2, KCNIP4, GPRI25, GBA SLC34A2, Q9BRT5, RBPSUH, CCKAR, TBCIDI9, STIM2

5.4 DB131, GAK19, ENK19, DRD5, SLC2A9, WDRI, HS3STI, HSP9OAB2P, RAB28, BAPXI, FAM44A, Q6PID2, CPEB2, CIQTNF7, $F B X L 5, B S T I, C D 38$

188.8 LRP2BP, ANKRD37, PDLIM3, SORBS2, TLR3, CYP4V2, KLKBI, FII, MTNRIA, FAT

$5 \quad|R X|$

85.5 BTF3, ANKRA2, UTPI 5, ENCI, HEXB, GFM2, TIPI, GCNT4, ANKRD3I, HMGCR, COL4A3BP, POLK, SV2C, IQGAP2, F2RL2, F2R, F2RLI, SIO0Z, CRHBP, AGGFI, ZBED3, PDE8B, WDR4I, OTP, TBCA, AP3BI, SCAMPI, LHFPL2, ARSB, DMGDH, BHMT2, BHMT, HOMERI, PAPD4, CMYA5, THBS4, SERINC5, ZFYVEI6, MSH3, RASGRF2, CKMT2, ZCCHC9, ACOTI 2, SSBP2, ATGIO, RPS23, XRCC4, CSPG2, HAPLNI, EDIL3

96.I NR2FI, ANKRD32, MCTPI, FAM8IB, ARSK, GPRI50, SPATA9, RHOBTB3, GLRX, ELL2, PCSKI, CAST

131.6

| 48.5

175.5

44.9

50.6

PPII, RAPGEF3, HDAC7A, VDR, TMEMI06C, COL2AI, SENPI, PFKM, ASB8, ORIOADI, HIFNT, ZNF64I, ANP32D, OR8SI, LALBA, CCNTI, ADCY6, CACNB3, DDX23, RNDI, CCDC65, FKBPII, ARF3, WNTIOB, WNTI, DDN, PRKAGI, MLL2, RHEBLI, DHH, LMBRIL, TBAK, TBA3, TUBA6, PRPH, TROAP, CIQL4, SPATS2, KCNH3, MCRSI, PRPF4OB, FMNL3, TEGT, FAIM2, AQP2, AQP5, AQP6, RACGAPI, SMARCDI, GPDI, LASS5, LIMAI, LARP4, DIP2B, ATFI, TMPRSSI2, METTL7A, SLCIIA2, LETMDI, TAII 2, TFCP2, POU6FI, DAZAP2, BIN2, ELAI, GALNT6, SLC4A8, SCN8A, ACVRIB, ANKRD33, ACVRLI

$13 q 14.2$

|3q21.1-q21.31

$|7 p| 1.2-q \mid 1.2$

60.8 PCDHI7, DIAPH3, TDRD3

30.3 KCN/12, FAM27L

extracted from frozen and formalin-fixed samples, this $14.3 \mathrm{Mb}$ telomeric region encompasses interesting oncogene candidates, such as $H-R A S$, a bona fide oncogene, and IGF2, which has been reported to show loss of imprinting in up to $30-60 \%$ of breast cancers (McCann et al, 1996; Wu et al, 1997). In the prechemotherapy samples, gain on $11 \mathrm{p} 15.2-\mathrm{p} 15.5$ was observed in five out of 10 good responders and in two out of 11 poor responders (not significant, Fisher's exact test).

\section{DISCUSSION}

In the present study, the frequency and pattern of unbalanced genomic aberrations were similar to those described in previous studies where genome-wide changes were analysed by means of chromosomal CGH (Tirkkonen et al, 1998; Buerger et al, 1999a, b; Roylance et al, 1999; Seute et al, 2001; Rennstam et al, 2003) and aCGH (Callagy et al, 2005; Naylor et al, 2005; Nessling et al, 2005). 

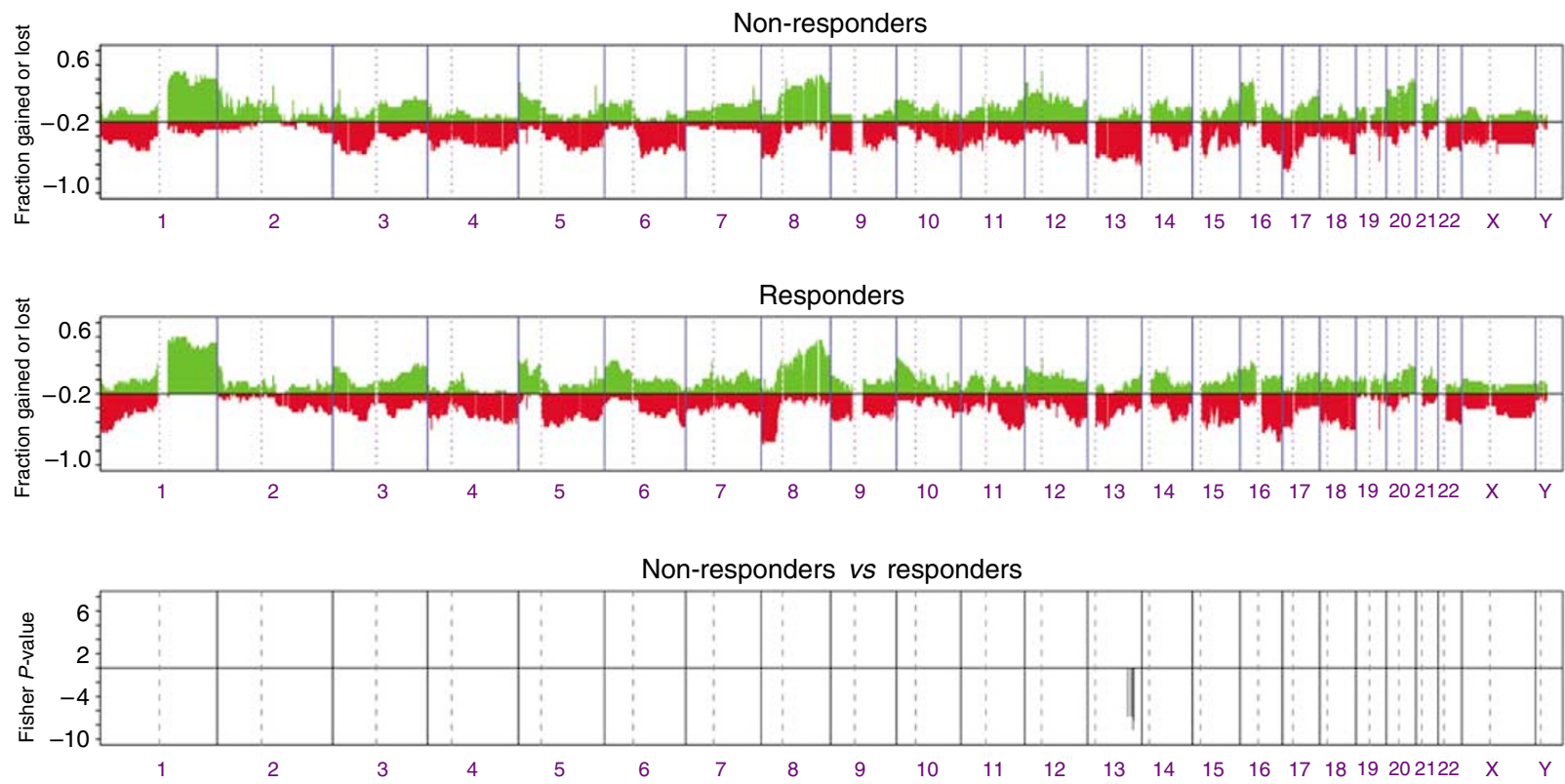

Figure 2 Categorical analysis of copy number gains and losses between non-responders $(N=20)$ and responders $(N=24)$. Fisher's exact tests are carried out on the segmented values for each clone, and those with a P-value of less than 0.0 I are plotted (inverse log 0 , $y$ axis) according to genomic location ( $x$ axis).

Recurrent gains on chromosome 1q, 8q, 11q, 17q and $20 \mathrm{q}$ and losses on $6 \mathrm{q}, 8 \mathrm{p}, 9 \mathrm{p}, 13 \mathrm{q}$ and $16 \mathrm{q}$ were the most prevalent changes. In addition, we confirmed the association between ER positivity and gain of 1q coupled with loss of 16q (Farabegoli et al, 2004; Reis-Filho et al, 2005a; Simpson et al, 2005) and the more prevalent deletions of $4 \mathrm{p} 16$ and $4 \mathrm{p} 15,5 \mathrm{q}$ and $17 \mathrm{p} 11.2$ in ERnegative tumours (Loo et al, 2004). In contrast to previous studies (Loo et al, 2004), gains of 8q24.1 (MYC) and 17q12 (HER2) were not significantly more frequent in ER-positive tumours. This is expected, given that only breast carcinomas of histological grades 2 and 3 were present in the population and gains of $8 \mathrm{q}$ are rather frequent in grade 2 and 3 breast cancers (Buerger et al, 1999a, b; Roylance et al, 1999).

The comparison between the genomic profiles obtained for ductal and lobular carcinomas were also in agreement with previous studies (Buerger et al, 1999b; Shelley Hwang et al, 2004; Reis-Filho et al, 2005a; Simpson et al, 2005; Stange et al, 2006): gain of $1 \mathrm{q}$ and deletions of $16 \mathrm{q}$ were the most prevalent changes in lobular carcinomas, whereas gain of $8 \mathrm{q}$ was significantly more frequent in grade 2 and 3 ductal carcinomas. However, we could define the smallest region of overlap of the deletions of 16q, which mapped to 16q21-q22.1 and encompassed the region of the cadherin gene cluster, and the gain of $8 \mathrm{q}$, which encompassed two regions 8q13.2-q21.13 and 8q21.3 - qtel (Supplementary Table 3). The most significant gain comparing ductal carcinoma with lobular carcinomas mapped to 8q24.11 (117.8-118.0 Mb), which encompasses RAD21 and eucaryotic translation initiation factor 3, subunit 3 gamma (EIF3S3). RAD21 is believed to function in sister chromatid alignment as part of the cohesin complex and also in double-strand break repair and influences cellular proliferation (Atienza et al, 2005), whereas EIF3S3 is reported to be amplified and overexpressed in up to $20 \%$ of breast carcinomas (Nupponen et al, 1999). Our observations are consistent with previous studies on breast cancer, confirming the robustness of our aCGH protocol, the validity of our analysis method and the likelihood that we have a representative set of tumours.

Several attempts have been made to predict clinical or pathological response to neoadjuvant chemotherapy in breast cancer using gene expression arrays. Gene 'signatures' or predictors have been devised for several chemotherapy regimens, including paclitaxel followed by fluorouracil, AC, AC/doxorubicindocetaxel and taxane only chemotherapy (Chang et al, 2003, 2005b; Ayers et al, 2004; Hannemann et al, 2005; Cleator et al, 2006). Although these results are promising, the exceedingly small sample size and limitations with the current technology and analysis methods have so far precluded definitive conclusions (Brenton et al, 2005; Reis-Filho et al, 2006b).

We have recently reported a similar expression profiling study (Cleator et al, 2006) that included the 44 patients studied here plus a small number of others for whom pretreatment tissue for DNA analysis was not available. Neither unsupervised nor supervised methods could separate the responders from non-responders. In the current study, using the same cohort of patients, which included 24 good clinical responders, aCGH analysis revealed a deletion of a large region from $13 \mathrm{q} 31.1$ to $13 \mathrm{q} 34$ as the only significant copy number change associated with response to chemotherapy. Although this statistical association lost its significance after correction for multiple comparisons, the correction method, which we adopted may be too conservative, given that unbalanced chromosomal aberrations usually encompass more than one BAC clone. One of the genes deleted in this region is a subtype of heat-shock protein 90, HSP90AB6. HSP 90 is a molecular chaperone whose association is required for stability and function of multiple signalling proteins that promote cancer cell growth and/or survival (Chen et al, 2005). Further studies with a larger sample size focusing on this particular region are warranted. We cannot exclude the possibility that analysis similar to ours of a larger series of samples might identify other DNA aberrations of importance for response to AC chemotherapy. It is however likely that if these were present in a large proportion of the population they would have been uncovered by the present analysis.

Sequential sampling of tumour during neoadjuvant treatment can be used to detect gene expression modification induced by therapy as we have demonstrated with endocrine therapy (Mackay et al, 2005). This was demonstrated for chemotherapy by Hannemann et al (2005), who observed that tumours that responded to neoadjuvant chemotherapy showed dramatic 

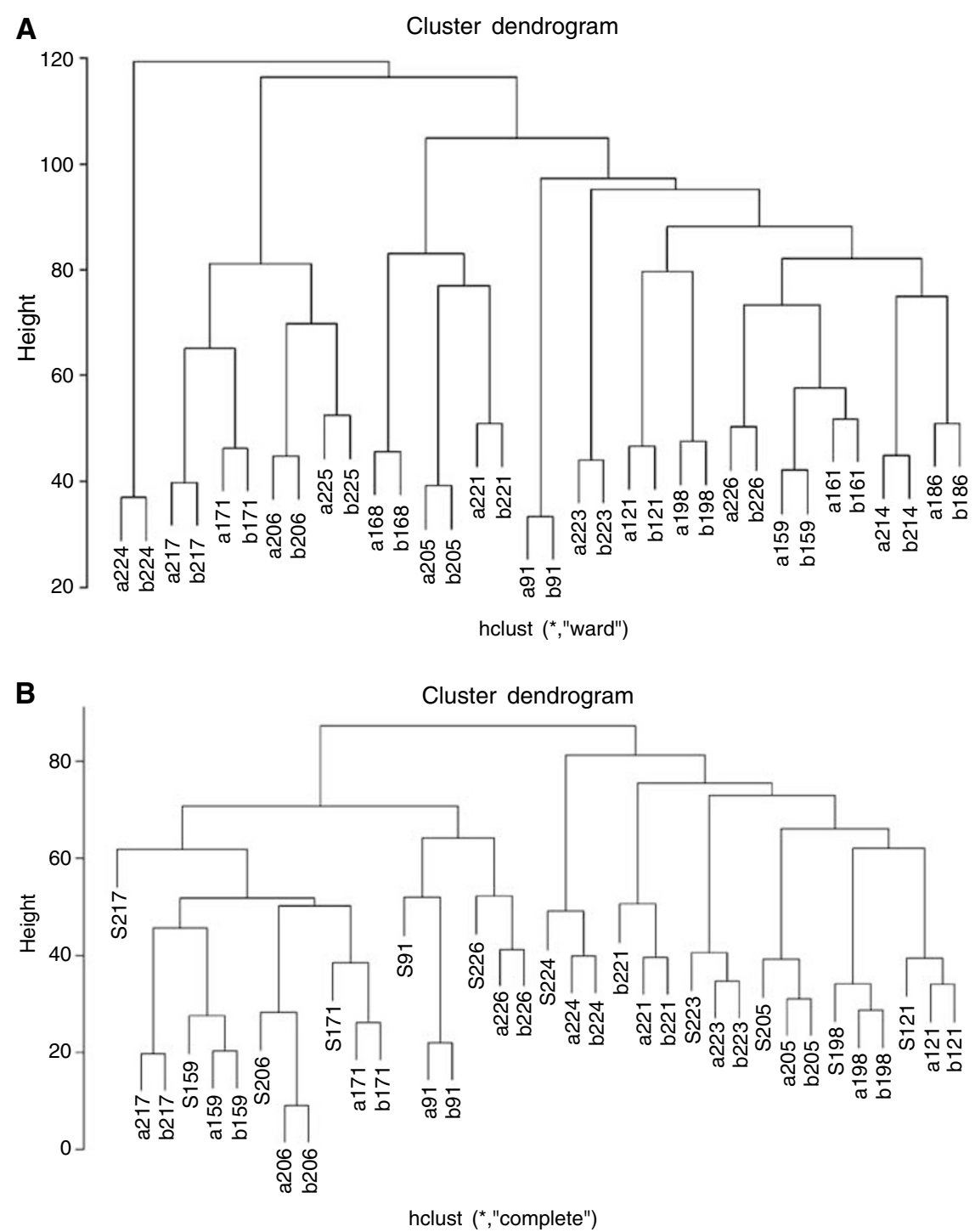

Figure 3 Hierarchical clustering analysis (Ward's method/Euclidean distance) of matched pre- and post-chemotherapy samples ( 17 patients) (A) and prechemotherapy, post-chemotherapy and surgical samples ( 12 patients) (B). (b - before chemotherapy; a - after chemotherapy (day 21 ); $\mathbf{s}$ - surgical biopsy).

changes in their expression profiles when compared to the changes observed in non-responders (Hannemann et al, 2005). On the other hand, a comparison between the transcriptomic profiles of tumours subjected to taxane-based neoadjuvant chemotherapy before and 3 months after treatment revealed strikingly different patterns, independent of initial sensitivity or resistance (Chang et al, 2005b).

Cell line studies have demonstrated that changes in gene copy numbers may lead to acquired resistance to chemotherapy (Leyland-Jones et al, 1999; Shimizu et al, 2002; Yasui et al, 2004). Specific gains of genetic material mapping to multi-drug resistance (MDR) gene MDR1 locus have been reported in drug resistant cell lines (Shimizu et al, 2002; Kuwano et al, 2003). Recurring amplicon 7q11.2-q21 identified by CGH in doxorubicin-resistant hepatocellular carcinoma cell lines coincided with the localisation of MDR1 (Pang et al, 2005). Induction of DNA damage response genes such as p21 were obtained by doxorubicin in breast cancer cell lines (Troester et al, 2004). Both chromosome 7 alterations and several cytogenetic changes involving the $7 \mathrm{q} 21$ locus are associated with the development of MDR in sarcoma cells (Chen et al, 2002). Analysis of genomic amplifications and deletions revealed specific genetic alterations common to both intrinsic and acquired doxorubicin resistance including $A B C B 1, P G Y 3(A B C B 4)$ and $B A K$ (Turton et al, 2001).

Most patients show some tumour shrinkage with neoadjuvant chemotherapy and for many there may be profound loss of malignant cells with some showing a pCR. Characterisation of the residual cells may be expected to a better understanding of the causes of resistance and allow the identification of the means to overcome the resistance. Given the molecular heterogeneity between breast carcinomas and the composition of most breast cancers being of multiple non-modal clones, we hypothesised that the cell loss might lead to selection of breast cancer cell lineages that were resistant to chemotherapy by virtue of specific DNA alterations. Few studies have previously addressed this issue. A very small study, involving CGH of just four tumours from breast cancer patients after neoadjuvant chemotherapy (Fazeny-Dorner et al, 2003) showed typical DNA imbalances for ductal breast cancer. Three patients showed involvement of several regions bearing genes of drug resistance (MDR1, BCRP, MRP1, RFC1); the fourth patient displayed an amplification in the region of MYC. 

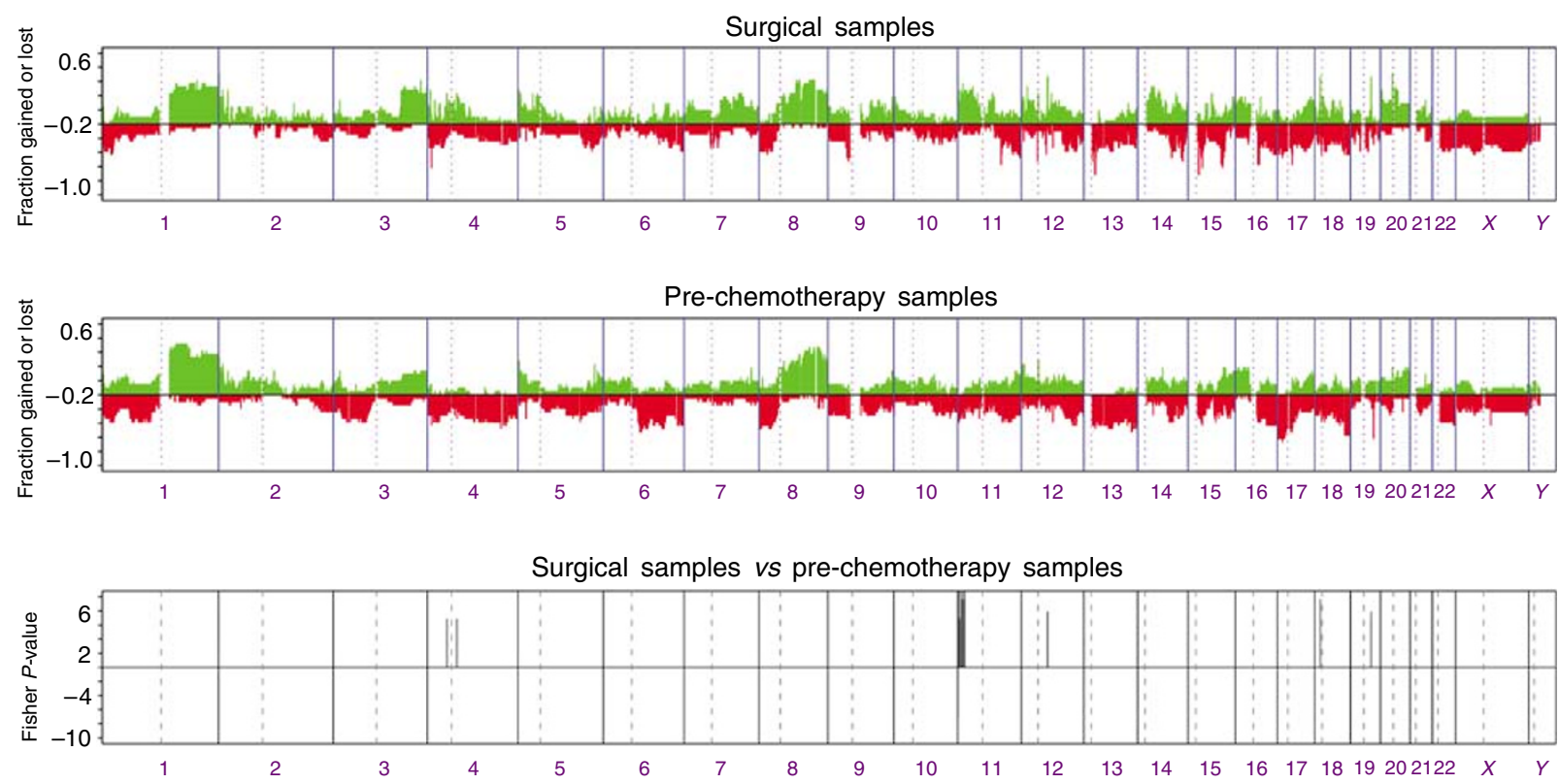

Figure 4 Categorical analysis of copy number gains and losses between matched pre-chemotherapy and surgical tumour samples (2I patients). Fisher's exact tests are carried out on the segmented values for each clone, and those with a $P$-value of less than 0.0 I are plotted (inverse log I $0, y$ axis) according to genomic location ( $x$ axis).

In our study, the hierarchical clustering of sequential samples at baseline, 3 weeks and at surgery indicated that any changes induced in DNA profiles by therapy were modest compared with the differences that were present between the patients. This interpretation was supported by the observation that statistically significant chemotherapy-driven genomic changes were not detected within 3 weeks (i.e. after a single course of chemotherapy). Comparison of the pretreatment and the tumour specimens excised after 4 months of neoadjuvant chemotherapy revealed the appearance of genomic gains on $11 \mathrm{p} 15.2-\mathrm{p} 15.5$. Given the experimental design of our study, we cannot define whether these amplifications were chemotherapy induced or were present in a non-modal population of the primary tumour and selected by chemotherapy, as the majority of surgical samples by definition were obtained from poor responders (66\%). Interestingly, pathological relaxation of the imprinting pattern in this region is reported to be found in 30-60\% of breast cancers (McCann et al, 1996; Wu et al, 1997). However we did not find a correlation between amplification on 11p15.5 and clinical response (Han et al, 2006). Furthermore, these changes on surgical samples, need to be cautiously interpreted as surgical samples were subjected to different fixation conditions (Devries et al, 2005). Thus in contrast

\section{REFERENCES}

Albertson DG (2003) Profiling breast cancer by array CGH. Breast Cancer Res Treat 78: $289-298$

Atienza JM, Roth RB, Rosette C, Smylie KJ, Kammerer S, Rehbock J, Ekblom J, Denissenko MF (2005) Suppression of RAD21 gene expression decreases cell growth and enhances cytotoxicity of etoposide and bleomycin in human breast cancer cells. Mol Cancer Ther 4: $361-368$

Ayers M, Symmans WF, Stec J, Damokosh AI, Clark E, Hess K, Lecocke M, Metivier J, Booser D, Ibrahim N, Valero V, Royce M, Arun B, Whitman G, Ross J, Sneige N, Hortobagyi GN, Pusztai L (2004) Gene expression profiles predict complete pathologic response to neoadjuvant paclitaxel and fluorouracil, doxorubicin, and cyclophosphamide chemotherapy in breast cancer. J Clin Oncol 22: 2284-2293 to observations with cancer cell lines, we did not find large or frequent chemotherapy-induced acquired genomic changes. Given that aCGH provides an average of the pattern of genomic gains and losses in the cell population studied, chemotherapy-driven losses or low-level gains occurring in non-modal clones are unlikely to be detected.

In conclusion, array CGH is a powerful method for the genomewide detection of chromosomal imbalances and allowed us to detect molecular genetic aberrations associated with specific breast cancer subgroups (ductal vs lobular, ER-negative vs ER-positive tumours). A molecular genetic profile specific of good responders to neoadjuvant chemotherapy was not detectable in our series. Chemotherapy-driven genomic changes were not detected following 3 weeks of treatment and only a single change after completion of treatment. The hypothesis of resistance to neoadjuvant chemotherapy by the selection of non-modal cell lineages, which differ by gene amplifications or losses is not supported by our results.

Supplementary Information accompanies the paper on British Journal of Cancer website (http://www.nature.com/bjc)
Brenton JD, Carey LA, Ahmed AA, Caldas C (2005) Molecular classification and molecular forecasting of breast cancer: ready for clinical application? J Clin Oncol 23: 7350 - 7360

Buerger H, Otterbach F, Simon R, Poremba C, Diallo R, Decker T, Riethdorf L, Brinkschmidt C, Dockhorn-Dworniczak B, Boecker W (1999a) Comparative genomic hybridization of ductal carcinoma in situ of the breast-evidence of multiple genetic pathways. J Pathol 187: 396-402

Buerger H, Otterbach F, Simon R, Schafer KL, Poremba C, Diallo R, Brinkschmidt C, Dockhorn-Dworniczak B, Boecker W (1999b) Different genetic pathways in the evolution of invasive breast cancer are associated with distinct morphological subtypes. J Pathol 189: 521-526

Callagy G, Pharoah P, Chin SF, Sangan T, Daigo Y, Jackson L, Caldas C (2005) Identification and validation of prognostic markers in breast 
cancer with the complementary use of array-CGH and tissue microarrays. J Pathol 205: 388-396

Chang JC, Hilsenbeck SG, Fuqua SAW (2005a) The promise of microarrays in the management and treatment of breast cancer. Breast Cancer Res 7: $100-104$

Chang JC, Wooten EC, Tsimelzon A, Hilsenbeck SG, Gutierrez MC, Elledge R, Mohsin S, Osborne CK, Chamness GC, Allred DC, O'Connell P (2003) Gene expression profiling for the prediction of therapeutic response to docetaxel in patients with breast cancer. Lancet 362: 362-369

Chang JC, Wooten EC, Tsimelzon A, Hilsenbeck SG, Gutierrez MC, Tham YL, Kalidas M, Elledge R, Mohsin S, Osborne CK, Chamness GC, Allred DC, Lewis MT, Wong H, O'Connell P (2005b) Patterns of resistance and incomplete response to docetaxel by gene expression profiling in breast cancer patients. J Clin Oncol 23: 1169-1177

Chen B, Piel WH, Gui L, Bruford E, Monteiro A (2005) The HSP90 family of genes in the human genome: insights into their divergence and evolution. Genomics 86: 627-637

Chen GK, Lacayo NJ, Duran GE, Wang Y, Bangs CD, Rea S, Kovacs M, Cherry AM, Brown JM, Sikic BI (2002) Preferential expression of a mutant allele of the amplified MDR1 (ABCB1) gene in drug-resistant variants of a human sarcoma. Genes Chromosomes Cancer 34: 372-383

Cleator S, Ashworth A (2004) Molecular profiling of breast cancer: clinical implications. Br J Cancer 90: $1120-1124$

Cleator S, Tsimelzon A, Ashworth A, Dowsett M, Dexter T, Powles T, Hilsenbeck S, Wong H, Osborne CK, O'Connell P, Chang JC (2006) Gene expression patterns for doxorubicin (Adriamycin) and cyclophosphamide (Cytoxan) (AC) response and resistance. Breast Cancer Res Treat 95: $229-233$

Davidson NE, Morrow M (2005) Sometimes a great notion - an assessment of neoadjuvant systemic therapy for breast cancer. J Natl Cancer Inst 97: $159-161$

Devries S, Nyante S, Korkola J, Segraves R, Nakao K, Moore D, Bae H, Wilhelm M, Hwang S, Waldman F (2005) Array-based comparative genomic hybridization from formalin-fixed, paraffin-embedded breast tumors. J Mol Diagn 7: 65-71

Dowsett M, Bartlett J, Ellis IO, Salter J, Hills M, Mallon E, Watters AD, Cooke T, Paish C, Wencyk PM, Pinder SE (2003) Correlation between immunohistochemistry (HercepTest) and fluorescence in situ hybridization (FISH) for HER-2 in 426 breast carcinomas from 37 centres. J Pathol 199: $418-423$

Dressman H, Hans C, Bild A, Olson Jr JA (2006) Gene expression profiles of multiple breast cancer phenotypes and response to neoadjuvant chemotherapy. Clin Cancer Res 12: 819-826

Farabegoli F, Hermsen MA, Ceccarelli C, Santini D, Weiss MM, Meijer GA, van Diest PJ (2004) Simultaneous chromosome 1q gain and 16q loss is associated with steroid receptor presence and low proliferation in breast carcinoma. Mod Pathol 17: 449-455

Fazeny-Dorner B, Piribauer M, Wenzel C, Fakhrai N, Pirker C, Berger W, Sedivy R, Rudas M, Filipits M, Okamoto I, Marosi C (2003) Cytogenetic and comparative genomic hybridization findings in four cases of breast cancer after neoadjuvant chemotherapy. Cancer Genet Cytogenet 146: $161-166$

Goldhirsch A, Glick JH, Gelber RD, Coates AS, Thurlimann B, Senn HJ (2005) Meeting highlights: international expert consensus on the primary therapy of early breast cancer 2005. Ann Oncol 16: 1569-1583

Han W, Han MR, Kang JJ, Bae JY, Lee JH, Bae YJ, Lee JE, Shin HJ, Hwang KT, Hwang SE, Kim SW, Noh DY (2006) Genomic alterations identified by array comparative genomic hybridization as prognostic markers in tamoxifentreated estrogen receptor-positive breast cancer. BMC Cancer 6: 92

Hannemann J, Oosterkamp HM, Bosch CA, Velds A, Wessels LF, Loo C, Rutgers EJ, Rodenhuis S, van de Vijver MJ (2005) Changes in gene expression associated with response to neoadjuvant chemotherapy in breast cancer. J Clin Oncol 23: 3331-3342

Hayashita Y, Osada H, Tatematsu Y, Yamada H, Yanagisawa K, Tomida S, Yatabe Y, Kawahara K, Sekido Y, Takahashi T (2005) A polycistronic microRNA cluster, miR-17-92, is overexpressed in human lung cancers and enhances cell proliferation. Cancer Res 65: 9628-9632

Hupe P, Stransky N, Thiery JP, Radvanyi F, Barillot E (2004) Analysis of array CGH data: from signal ratio to gain and loss of DNA regions. Bioinformatics 20: $3413-3422$

Ioannidis JP (2005) Microarrays and molecular research: noise discovery? Lancet 365: $454-455$

Iwao-Koizumi K, Matoba R, Ueno N, Kim SJ, Ando A, Miyoshi Y, Maeda E, Noguchi S, Kato K (2005) Prediction of docetaxel response in human breast cancer by gene expression profiling. J Clin Oncol 23: 422-431
Kuwano M, Uchiumi T, Hayakawa H, Ono M, Wada M, Izumi H, Kohno K (2003) The basic and clinical implications of ABC transporters, Y-boxbinding protein-1 (YB-1) and angiogenesis-related factors in human malignancies. Cancer Sci 94: 9-14

Leyland-Jones B, Kelland LR, Harrap KR, Hiorns LR (1999) Genomic imbalances associated with acquired resistance to platinum analogues. Am J Pathol 155: 77 -84

Loo LW, Grove DI, Williams EM, Neal CL, Cousens LA, Schubert EL, Holcomb IN, Massa HF, Glogovac J, Li CI, Malone KE, Daling JR, Delrow JJ, Trask BJ, Hsu L, Porter PL (2004) Array comparative genomic hybridization analysis of genomic alterations in breast cancer subtypes. Cancer Res 64: 8541 - 8549

Mackay A, Dixon JM, Urruticoechea A, Dexter T, Iravani M, Fenwick K, Young O, White S, Miller WR, Evans DB, Ashworth A, Dowsett M (2005) Molecular determinants of aromatase inhibitor sensitivity in primary breast cancer. Breast Cancer Res Treat 94: S48 (abstract)

McCann AH, Miller N, O’Meara A, Pedersen I, Keogh K, Gorey T, Dervan PA (1996) Biallelic expression of the IGF2 gene in human breast disease. Hum Mol Genet 5: 1123-1127

Modlich O, Prisack HB, Munnes M, Audretsch W, Bojar H (2005) Predictors of primary breast cancers responsiveness to preoperative epirubicin/ cyclophosphamide-based chemotherapy: translation of microarray data into clinically useful predictive signatures. J Transl Med 3: 32

Natrajan R, Williams RD, Hing SN, Mackay A, Reis-Filho JS, Fenwick K, Iravani $\mathrm{M}$, Valgeirsson h, Grigoriadis A, Langford CF, Dovey O, Gregory SG, Weber BL, Ashworth A, Grundy PE, Pritchard-Jones K, Jones C (2006) Array CGH profiling of favourable histology wilms tumours reveals novel gains and losses associated with relapse. J Pathol 210: $49-58$

Naylor TL, Greshock J, Wang Y, Colligon T, Yu QC, Clemmer V, Zaks TZ, Weber BL (2005) High resolution genomic analysis of sporadic breast cancer using array-based comparative genomic hybridization. Breast Cancer Res 7: R1186-R1198

Nessling M, Richter K, Schwaenen C, Roerig P, Wrobel G, Wessendorf S, Fritz B, Bentz M, Sinn HP, Radlwimmer B, Lichter P (2005) Candidate genes in breast cancer revealed by microarray-based comparative genomic hybridization of archived tissue. Cancer Res 65: $439-447$

Nupponen NN, Porkka K, Kakkola L, Tanner M, Persson K, Borg A, Isola J, Visakorpi T (1999) Amplification and overexpression of p40 subunit of eukaryotic translation initiation factor 3 in breast and prostate cancer. Am J Pathol 154: 1777-1783

O'Connell P (2003) Genetic and cytogenetic analyses of breast cancer yield different perspectives of a complex disease. Breast Cancer Res Treat 78: $347-357$

Pang E, Hu Y, Chan KY, Lai PB, Squire JA, Macgregor PF, Beheshti B, Albert M, Leung TW, Wong N (2005) Karyotypic imbalances and differential gene expressions in the acquired doxorubicin resistance of hepatocellular carcinoma cells. Lab Invest 85: 664-674

Paris PL, Andaya A, Fridlyand J, Jain AN, Weinberg V, Kowbel D, Brebner JH, Simko J, Watson JE, Volik S, Albertson DG, Pinkel D, Alers JC, van der Kwast TH, Vissers KJ, Schroder FH, Wildhagen MF, Febbo PG, Chinnaiyan AM, Pienta KJ, Carroll PR, Rubin MA, Collins C, van Dekken $\mathrm{H}$ (2004) Whole genome scanning identifies genotypes associated with recurrence and metastasis in prostate tumors. Hum Mol Genet 13: $1303-1313$

Ransohoff DF (2004) Rules of evidence for cancer molecular-marker discovery and validation. Nat Rev Cancer 4: 309-314

Reis-Filho JS, Simpson PT, Gale T, Lakhani SR (2005a) The molecular genetics of breast cancer: the contribution of comparative genomic hybridization. Pathol Res Pract 201: 713-725

Reis-Filho JS, Simpson PT, Jones C, Steele D, Mackay A, Iravani M, Fenwick K, Valgeirsson H, Lambros M, Ashworth A, Palacios J, Schmitt F, Lakhani SR (2005b) Pleomorphic lobular carcinoma of the breast: role of comprehensive molecular pathology in characterization of an entity. J Pathol 207: 1 - 13

Reis-Filho JS, Simpson PT, Turner NC, Lambros MB, Jones C, Mackay A, Grigoriadis A, Sarrio D, Savage K, Dexter T, Iravani M, Fenwick K, Weber B, Hardisson D, Schmitt FC, Palacios J, Lakhani SR, Ashworth A (2006a) Comprehensive molecular genetic analysis reveals FGFR1 as a potential therapeutic target for lobular breast carcinomas. Clin Cancer Res 12: doi:10.1158/1078-0432.CCR-06-1164

Reis-Filho JS, Westbury C, Pierga JY (2006b) The impact of expression profiling on prognostic and predictive testing in breast cancer. $J$ Clin Pathol 59: 225-231 
Rennstam K, Ahlstedt-Soini M, Baldetorp B, Bendahl PO, Borg A, Karhu R, Tanner M, Tirkkonen M, Isola J (2003) Patterns of chromosomal imbalances defines subgroups of breast cancer with distinct clinical features and prognosis. A study of 305 tumors by comparative genomic hybridization. Cancer Res 63: $8861-8868$

Rouzier R, Perou CM, Symmans WF, Ibrahim N, Cristofanilli M, Anderson K, Hess KR, Stec J, Ayers M, Wagner P, Morandi P, Fan C, Rabiul I, Ross JS, Hortobagyi GN, Pusztai L (2005) Breast cancer molecular subtypes respond differently to preoperative chemotherapy. Clin Cancer Res 11: $5678-5685$

Roylance R, Gorman P, Harris W, Liebmann R, Barnes D, Hanby A, Sheer D (1999) Comparative genomic hybridization of breast tumors stratified by histological grade reveals new insights into the biological progression of breast cancer. Cancer Res 59: 1433-1436

Seute A, Sinn HP, Schlenk RF, Emig R, Wallwiener D, Grischke EM, Hohaus S, Dohner H, Haas R, Bentz M (2001) Clinical relevance of genomic aberrations in homogeneously treated high-risk stage II/III breast cancer patients. Int J Cancer 93: 80-84

Shelley Hwang E, Nyante SJ, Yi Chen Y, Moore D, DeVries S, Korkola JE, Esserman LJ, Waldman FM (2004) Clonality of lobular carcinoma in situ and synchronous invasive lobular carcinoma. Cancer 100: $2562-2572$

Shimizu H, Fukuda T, Ghazizadeh M, Nagashima M, Kawanami O, Suzuki $\mathrm{T}$ (2002) Molecular cytogenetic characterization of drug-resistant leukemia cell lines by comparative genomic hybridization and fluorescence in situ hybridization. Jpn J Cancer Res 93: 902-910

Simpson PT, Reis-Filho JS, Gale T, Lakhani SR (2005) Molecular evolution of breast cancer. J Pathol 205: 248-254
Stange DE, Radlwimmer B, Schubert F, Traub F, Pich A, Toedt G, Mendrzyk F, Lehmann U, Eils R, Kreipe H, Lichter P (2006) High-resolution genomic profiling reveals association of chromosomal aberrations on 1q and $16 \mathrm{p}$ with histologic and genetic subgroups of invasive breast cancer. Clin Cancer Res 12: $345-352$

Tirkkonen M, Tanner M, Karhu R, Kallioniemi A, Isola J, Kallioniemi OP (1998) Molecular cytogenetics of primary breast cancer by CGH. Genes Chromosomes Cancer 21: 177-184

Troester MA, Hoadley KA, Sorlie T, Herbert BS, Borresen-Dale AL, Lonning PE, Shay JW, Kaufmann WK, Perou CM (2004) Cell-type-specific responses to chemotherapeutics in breast cancer. Cancer Res 64: 4218 4226

Troyanskaya O, Cantor M, Sherlock G, Brown P, Hastie T, Tibshirani R, Botstein D, Altman RB (2001) Missing value estimation methods for DNA microarrays. Bioinformatics 17: 520-525

Turton NJ, Judah DJ, Riley J, Davies R, Lipson D, Styles JA, Smith AG, Gant TW (2001) Gene expression and amplification in breast carcinoma cells with intrinsic and acquired doxorubicin resistance. Oncogene 20: 1300 1306

van't Veer LJ, Paik S, Hayes DF (2005) Gene expression profiling of breast cancer: a new tumor marker. J Clin Oncol 23: $1631-1635$

Wu HK, Squire JA, Catzavelos CG, Weksberg R (1997) Relaxation of imprinting of human insulin-like growth factor II gene, IGF2, in sporadic breast carcinomas. Biochem Biophys Res Commun 235: 123-129

Yasui K, Mihara S, Zhao C, Okamoto H, Saito-Ohara F, Tomida A, Funato T, Yokomizo A, Naito S, Imoto I, Tsuruo T, Inazawa J (2004) Alteration in copy numbers of genes as a mechanism for acquired drug resistance. Cancer Res 64: $1403-1410$ 